Research Article

\title{
Establishment and Validation of Novel Clinical Prognosis Nomograms for Luminal A Breast Cancer Patients with Bone Metastasis
}

\author{
QiHao Tu $\mathbb{D}^{1}{ }^{1}$ Chuan Hu, ${ }^{1}$ Hao Zhang, ${ }^{1}$ Chen Peng, ${ }^{1}$ Meng Kong, ${ }^{1}$ MengXiong Song, \\ Chong Zhao, ${ }^{1}$ YuJue Wang, ${ }^{2}$ Jianyi Li, ${ }^{1}$ ChuanLi Zhou, ${ }^{1}$ Chao Wang, ${ }^{1}$ and XueXiao Ma ${ }^{1}$ \\ ${ }^{1}$ Department of Orthopaedic Surgery, The Affiliated Hospital of Qingdao University, Qingdao 266071, China \\ ${ }^{2}$ Medical College of Qingdao University, Qingdao, 266000 Shandong, China \\ Correspondence should be addressed to XueXiao Ma; drmaxuexiao@163.com
}

Received 18 August 2020; Revised 17 October 2020; Accepted 28 November 2020; Published 8 December 2020

Academic Editor: Xiangqian Guo

Copyright (c) 2020 Qi Hao Tu et al. This is an open access article distributed under the Creative Commons Attribution License, which permits unrestricted use, distribution, and reproduction in any medium, provided the original work is properly cited.

Purpose. Overall survival (OS) and cancer-specific survival (CSS) of luminal A breast cancer (BC) patients with bone metastasis remain poor and vary dramatically from person to person. Our goal was to build two universally applicable nomograms to accurately predict OS and CSS for luminal A patients with bone metastasis. Methods. The data were collected from the Surveillance, Epidemiology, and End Results (SEER) database for luminal A BC patients with bone metastasis between 2010 and 2015. Univariate and multivariate Cox regression analyses were to assess and identify independent risk factors of OS and CSS. Integrating all significant predictors, nomograms and risk group stratification model was developed. The performance of the nomogram was validated with concordance index (C-index), calibration plots, and decision curve analyses (DCA) for discriminative ability, calibration, and clinical utility, respectively. Results. 3171 luminal A BC patients with bone metastasis were included. Through univariate and multivariate Cox regression analyses, 12 variables were identified as both independent OS- and CSS-related factors, including age, race, primary site, histology grade, tumor size, surgery, brain metastasis, liver metastasis, lung metastasis, estrogen receptor status, progesterone receptor status, and insurance. Our nomograms for 1-, 3-, and 5-year survival were based on those significant prognostic factors to develop. The C-indexes of OS- and CSS-nomograms in the training cohort were 0.701 and 0.704 , respectively. Similar results were obtained in the validation cohort. The calibration curves and DCA presented satisfactory calibration and clinical utility. Conclusion. Two nomograms have good discrimination, calibration, and clinical utility, can accurately and effectively predict the prognosis of patients, and may benefit for clinical decision-making. In high-risk patients, more aggressive therapy and closer surveillance should be considered.

\section{Background}

Breast cancer $(\mathrm{BC})$ is the second most diagnosed cancer (11.6\% of the cancer cases), second only to lung cancer, and accounts for a quarter of all female cancer cases [1]. Among females, BC is not only the most generally diagnosed cancer but also the main cause of cancer death [1]. The wellknown classification criteria of breast cancer are depending on the status of molecular markers ER (estrogen receptor), PR (progesterone receptor), Ki-67, and Her2 (human epidermal growth factor receptor 2) [2]. BCs can be divided into molecular subtypes of Triple negative, luminal A, Luminal
B, and HER2, with luminal A subtype being the most common one [3].

The main cause of death for BC patients is not the primary tumor but the occurrence of distant metastasis [4]. A cancer statistic among Hispanics/Latinos showed approximately over $30 \%$ of BC patients would have distant nonnodal metastases [5]. A population-based research including about 300,000 patients indicated that the bone metastasis (3.28\%) takes the leading place in distant metastasis secondary to BC, which will develop in almost $3 / 4$ of stage-IV BC patients [6], negatively affecting the patient's mobility, survival expectancy, and life quality. Poor prognosis is largely caused by 


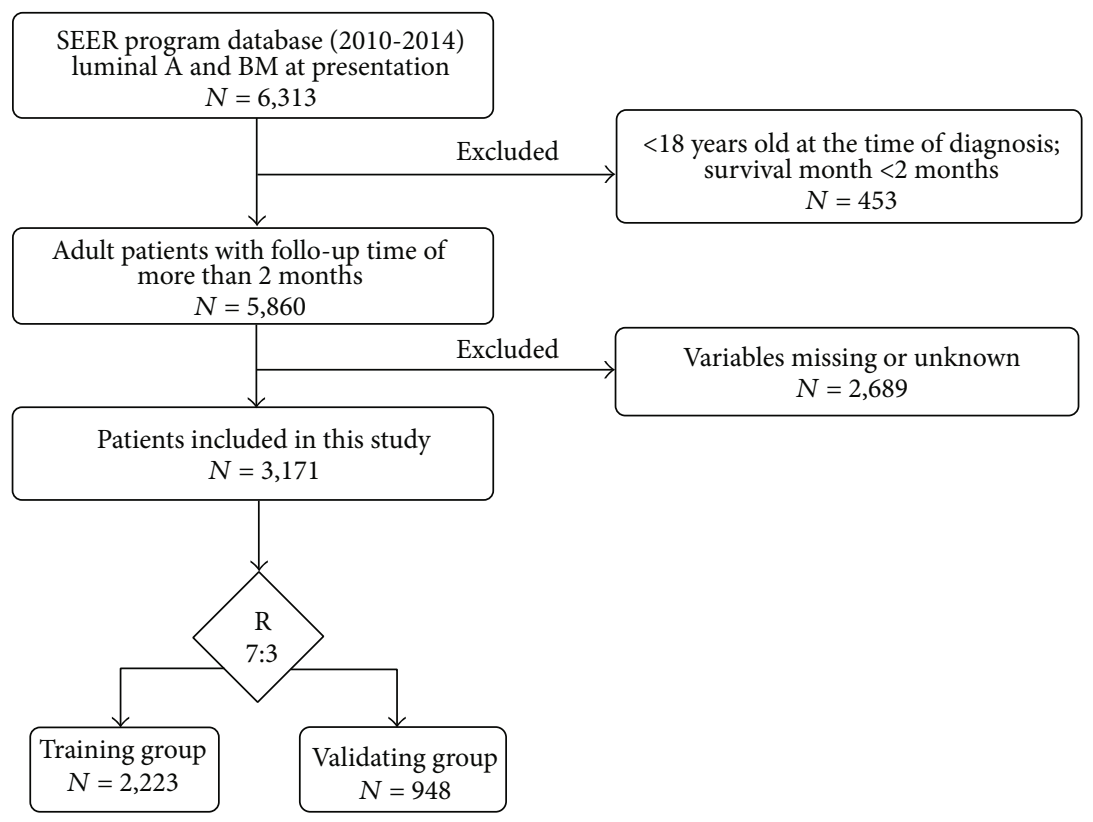

FIGURE 1: Flowchart of patient selection.

skeletal-related events (SRE), mainly presenting as severe pain, pathologic fractures, spinal cord compression, and hypercalcemia $[7,8]$.

Indeed, tumor treatment has made great progress as medical technology further develops. However, accurate prediction and standard treatments for luminal A subtype $\mathrm{BC}$ patients with bone metastasis are lacking. Moreover, limitations of conventional predictors including RPA/GPA classification and TMN stage, old risk grouping, regression tree analyses, or probability tables have gradually been revealed. To supply the most appropriate and feasible clinical treatment, there is an urgent need for a convenient and effective tool to accurately predict prognosis. With advantages compared to old predictors, nomograms have been applied effectively for a long time in outcomes predicting based on data collected from clinics and laboratories $[9,10]$. Furthermore, in several disciplines, studies, which compared different models have shown that nomograms based upon univariate and multivariate Cox regression are superior to other methodologies [11]. As a popular and effective prediction model, nomogram enables clinicians to evaluate the prognosis and choose an optimized treatment plan. The study is to develop new nomograms to predict the prognosis of luminal A subtype BC patients with bone metastasis.

\section{Methods}

2.1. Patient Selection and Grouping. The demographics, clinical and laboratory information of the luminal A patients with bone metastasis in the Surveillance, Epidemiology, and End Results (SEER) database from 2010 to June 2015 were collected. There is no need for informed consent in our study since the unidentified data was free from medical ethics review. The inclusion criteria were as follows: (1) patients diagnosed by immunohistochemistry; (2) patients with primary luminal A BC; (3) patients with bone metastasis. The exclusion criteria were as follows: (1) under 18 years old when diagnosed; (2) follow-up time $<2$ months; (3) key information lacking. Finally, 3171 patients were selected and randomly allocated into two groups by $\mathrm{R}$ software with a ratio of $7: 3$. Descriptive statistics were used to summarize the status and the features of the training and validation datasets.

2.2. Variable Selection and Declaration. Following variables were selected in our study: follow time, tumor size, race, gender, age at diagnosis, primary site, grade, laterality, histologic type, T, N stage, treatment, metastasis, cause of death, status of life, ER, PR, treatment marital, and insurance. Some variables were analyzed and adjusted considering their type, performance, and occurrence rates in clinical manifestation, as well as the actual data volume. Tumor size was regrouped into three subcollections (below $36 \mathrm{~mm}, 36-85 \mathrm{~mm}$, and above $85 \mathrm{~mm}$ ). Patients were then divided into three subcollections based on their ages $(<55,55-78$, and $>78)$. Race was classified as white, black, or others. Histology was divided as infiltrating duct carcinoma (IDC), infiltrating duct and lobular carcinoma (IDC+ILC), or others. The primary site was stratified as lower-inner, upper-inner, or lower-outer quadrant of the breast, central portion of the breast, breast NOS, and others. $\mathrm{T}$ stage was regrouped into two subgroups (T1-2 and T3-4). $\mathrm{N}$ stage was regrouped into two subgroups (N0 and N1-3).

2.3. Nomogram Development and Statistical Analyses. Patients who had no ending events during the follow-up were also included in the analysis. OS or CSS was 
TABLE 1: Demographic, clinical, and laboratory features of patients diagnosed as luminal A with bone metastasis.

\begin{tabular}{|c|c|c|c|}
\hline Variable & Training set $(n=2,223)$ & Validating set $(n=948)$ & $P$ value \\
\hline \multicolumn{4}{|l|}{ Follow time (mo) } \\
\hline Mean & 30.4 & 29.8 & \\
\hline Range & $2-83$ & $2-83$ & \\
\hline \multicolumn{4}{|l|}{ Number of events } \\
\hline Live & $1059(47.6 \%)$ & $462(48.7 \%)$ & \\
\hline Dead & $1164(52.4 \%)$ & $486(51.3 \%)$ & \\
\hline Age $(y)$ & & & 0.387 \\
\hline$<55$ & $776(34.9 \%)$ & $307(32.4 \%)$ & \\
\hline $55-78$ & $1220(54.9 \%)$ & $539(56.9 \%)$ & \\
\hline$>78$ & $227(10.2 \%)$ & $102(10.8 \%)$ & \\
\hline Race & & & 0.748 \\
\hline White & $1743(78.4 \%)$ & $742(78.3 \%)$ & \\
\hline Black & $300(13.5 \%)$ & $135(14.2 \%)$ & \\
\hline Other & $180(8.1 \%)$ & $71(7.5 \%)$ & \\
\hline Grade & & & 0.340 \\
\hline I & $292(13.1 \%)$ & $121(12.8 \%)$ & \\
\hline II & $1190(53.5 \%)$ & $520(54.9 \%)$ & \\
\hline III & $734(33.0 \%)$ & $307(32.4 \%)$ & \\
\hline IV & $7(0.3 \%)$ & 0 & \\
\hline Laterality & & & 0.260 \\
\hline Left & $1138(51.2 \%)$ & $474(50.0 \%)$ & \\
\hline Right & $1085(48.8 \%)$ & $473(49.9 \%)$ & \\
\hline Bilateral & 0 & $1(0.01 \%)$ & \\
\hline Histological type & & & 0.731 \\
\hline IDC & $1607(72.3 \%)$ & $678(71.5 \%)$ & \\
\hline IDC + ILC & $136(6.1 \%)$ & $65(6.9 \%)$ & \\
\hline Other & $480(21.6 \%)$ & $205(21.6 \%)$ & \\
\hline T stage & & & 0.806 \\
\hline $\mathrm{T} 1-2$ & $1183(53.2 \%)$ & $509(53.7 \%)$ & \\
\hline T3-4 & $1040(46.8 \%)$ & $439(46.3 \%)$ & \\
\hline N stage & & & 0.867 \\
\hline No & $522(23.5 \%)$ & $220(23.2 \%)$ & \\
\hline $\mathrm{N} 1-3$ & $1701(76.5 \%)$ & $728(76.8 \%)$ & \\
\hline Size $(\mathrm{mm})$ & & & 0.083 \\
\hline$<36$ & $973(43.8 \%)$ & $454(47.9 \%)$ & \\
\hline $36-85$ & $1019(45.8 \%)$ & $396(41.8 \%)$ & \\
\hline$>85$ & $231(10.4 \%)$ & $98(10.3 \%)$ & \\
\hline Primary site & & & 0.134 \\
\hline Breast, NOS & $487(21.9 \%)$ & $252(26.6 \%)$ & \\
\hline Central portion of breast & $180(8.1 \%)$ & $66(7.0 \%)$ & \\
\hline Lower-inner quadrant of breast & $94(4.2 \%)$ & $41(4.3 \%)$ & \\
\hline Lower-outer quadrant of breast & $140(6.3 \%)$ & $55(5.8 \%)$ & \\
\hline Upper-inner quadrant of breast & $179(8.1 \%)$ & $64(6.8 \%)$ & \\
\hline Upper-outer quadrant of breast & $619(27.8 \%)$ & $248(26.2 \%)$ & \\
\hline Other & $524(23.6 \%)$ & $222(23.4 \%)$ & \\
\hline Surgery & & & 0.734 \\
\hline Yes & $849(38.2 \%)$ & $356(37.6 \%)$ & \\
\hline No & $1374(61.8 \%)$ & $592(62.4 \%)$ & \\
\hline
\end{tabular}


TABLE 1: Continued.

\begin{tabular}{|c|c|c|c|}
\hline Variable & Training set $(n=2,223)$ & Validating set $(n=948)$ & $P$ value \\
\hline Radiation & & & $<0.0001$ \\
\hline Yes & $962(43.3 \%)$ & $516(54.4 \%)$ & \\
\hline No & $1261(56.7 \%)$ & $432(45.6 \%)$ & \\
\hline Chemotherapy & & & 0.322 \\
\hline Yes & $1058(47.6 \%)$ & $433(45.7 \%)$ & \\
\hline No & $1165(52.4 \%)$ & $515(54.3 \%)$ & \\
\hline Brain & & & 0.009 \\
\hline Yes & $103(4.6 \%)$ & $25(2.6 \%)$ & \\
\hline No & $2120(95.4 \%)$ & $923(97.4 \%)$ & \\
\hline Liver & & & 0.026 \\
\hline Yes & $347(15.6 \%)$ & $119(12.6 \%)$ & \\
\hline No & $1876(84.4 \%)$ & $829(87.4 \%)$ & \\
\hline Lung & & & 0.947 \\
\hline Yes & $469(21.1 \%)$ & $199(21.0 \%)$ & \\
\hline No & $1754(78.9 \%)$ & $749(79.0 \%)$ & \\
\hline$E R$ & & & 0.097 \\
\hline Positive & $2208(99.3 \%)$ & $936(98.7 \%)$ & \\
\hline Negative & $15(0.7 \%)$ & $12(1.3 \%)$ & \\
\hline$P R$ & & & 0.973 \\
\hline Positive & $1903(85.6 \%)$ & $813(85.8 \%)$ & \\
\hline Negative & $317(14.3 \%)$ & $134(14.1 \%)$ & \\
\hline Borderline & $3(0.1 \%)$ & $1(0.1 \%)$ & \\
\hline Insurance & & & 0.007 \\
\hline Yes & $2127(95.7 \%)$ & $926(97.7 \%)$ & \\
\hline No & $96(4.3 \%)$ & $22(2.3 \%)$ & \\
\hline Marital status & & & 0.004 \\
\hline Yes & $1127(50.7 \%)$ & $428(45.1 \%)$ & \\
\hline No & $1096(49.3 \%)$ & $520(54.9 \%)$ & \\
\hline
\end{tabular}

recognized as the endpoint of the study. OS was calculated from diagnosis to death led by any cause or the end of follow-up while CSS was from diagnosis to death caused by cancer [12]. Baseline characteristics comparison was performed by chi-square test, and risk factors for OS or CSS were evaluated by univariate Cox regression. Multivariate Cox regression was then conducted based on the results of univariate analysis. As a set of independent prognostic factors get screened, the nomograms for the OS and CSS of 1, 3, and 5 years were further constructed.

Aiming at the most simplified model with the strongest predicting capability, we conducted the establishment of the model under rigorous programmable decision so that its building procedure could get internally validated [13]. Meanwhile, we validated the models internally with the 1000 bootstrap resamples and conducted external validation on the validation cohort. The level of discrimination in this cohort was quantified and measured using the concordance index (C-index) and its 95\% confidence interval (95\% CI). The model's distinguishing ability improves when its C-index increases from 0.5 to 1 .The maximum value of the C-index is 1.0 , which indicates the model's perfect ability in correctly discriminating outcome. The consistency of the predicted results with the actual was further determined by the Calibration plot. Subsequently, the clinical utility of the nomogram was assessed by decision curve analysis (DCA) by quantifying quantified net benefits under various threshold probabilities [14], which was decided by the difference between the expected benefit and expected lose in association with every treatment strategy and proposed testing [15]. The patients of the training and validation datasets were categorized into groups of high-risk or low-risk in line with their nomogram-derived risk scores. The survival curve upon a log-rank test was used to evaluate the utility of nomogram in prognosis predicting. $\mathrm{R}$ software (http:// www.r-poject.org, version 3.6.1) and the IBM SPSS 25.0 software were applied for all statistical analyses as above.

\section{Results}

3.1. Grouping and Baseline Characteristics. The flow chart of the process of patient inclusion, exclusion, and grouping is shown in Figure 1. According to the criteria in the 
TABLE 2: Univariate Cox regression analysis of overall survival and cancer-specific survival in the training group.

\begin{tabular}{|c|c|c|c|c|c|c|}
\hline \multirow{2}{*}{ Variable } & \multicolumn{3}{|c|}{ OS } & \multicolumn{3}{|c|}{ CSS } \\
\hline & HR & $95 \% \mathrm{CI}$ & $\mathrm{P}$ & HR & $95 \% \mathrm{CI}$ & $\mathrm{P}$ \\
\hline \multicolumn{7}{|l|}{ Age (y) } \\
\hline$<55$ & Reference & & & Reference & & \\
\hline $55-78$ & 1.230 & $1.082-1.399$ & 0.002 & 1.215 & $1.045-1.413$ & 0.011 \\
\hline$>78$ & 2.187 & $1.812-2.639$ & 0.000 & 1.922 & $1.542-2.397$ & 0.000 \\
\hline \multicolumn{7}{|l|}{ Size $(\mathrm{mm})$} \\
\hline$<36$ & Reference & & & Reference & & \\
\hline $36-85$ & 1.154 & $1.020-1.305$ & 0.023 & 1.143 & $1.004-1.302$ & 0.043 \\
\hline$>85$ & 1.601 & $1.327-1.933$ & 0.000 & 1.644 & $1.351-1.999$ & 0.000 \\
\hline \multicolumn{7}{|l|}{ Race } \\
\hline Black & Reference & & & Reference & & \\
\hline Other & 0.614 & $0.478-0.790$ & 0.000 & 0.667 & $0.514-0.866$ & 0.002 \\
\hline White & 0.575 & $0.491-0.672$ & 0.000 & 0.590 & $0.499-0.697$ & 0.000 \\
\hline \multicolumn{7}{|l|}{ Primary site } \\
\hline Breast, NOS & Reference & & & Reference & & \\
\hline Central portion & 0.670 & $0.522-0.860$ & 0.002 & 0.684 & $0.527-0.888$ & 0.004 \\
\hline Lower-outer quadrant & 0.803 & $0.677-0.952$ & 0.011 & 0.788 & $0.659-0.943$ & 0.009 \\
\hline \multicolumn{7}{|l|}{ Grade } \\
\hline I & Reference & & & Reference & & \\
\hline II & 1.319 & $1.082-1.607$ & 0.006 & 1.301 & $1.056-1.603$ & 0.014 \\
\hline III & 1.885 & $1.539-2.309$ & 0.000 & 1.937 & $1.564-2.398$ & 0.000 \\
\hline IV & 2.478 & $1.091-5.628$ & 0.030 & 2.746 & $1.206-6.252$ & 0.016 \\
\hline \multicolumn{7}{|l|}{ T stage } \\
\hline $\mathrm{T} 1, \mathrm{~T} 2$ & Reference & & & Reference & & \\
\hline $\mathrm{T} 3, \mathrm{~T} 4$ & 1.299 & $1.157-1.457$ & 0.000 & 1.288 & $1.141-1.454$ & 0.000 \\
\hline \multicolumn{7}{|l|}{ Surgery } \\
\hline No & Reference & & & Reference & & \\
\hline Yes & 0.539 & $0.476-0.609$ & 0.000 & 0.533 & $0.468-0.608$ & 0.000 \\
\hline \multicolumn{7}{|l|}{ Chemotherapy } \\
\hline No & Reference & & & & & \\
\hline Yes & 0.859 & $0.765-0.964$ & 0.010 & & & \\
\hline \multicolumn{7}{|l|}{ Brain metastasis } \\
\hline No & Reference & & & Reference & & \\
\hline Yes & 2.506 & $1.996-3.147$ & 0.000 & 2.607 & $2.060-3.299$ & 0.000 \\
\hline \multicolumn{7}{|l|}{ Liver metastasis } \\
\hline No & Reference & & & Reference & & \\
\hline Yes & 2.174 & $1.884-2.509$ & 0.000 & 2.330 & $2.010-2.701$ & 0.000 \\
\hline \multicolumn{7}{|l|}{ Lung metastasis } \\
\hline No & Reference & & & Reference & & \\
\hline Yes & 1.666 & $1.463-1.898$ & 0.000 & 1.642 & $1.431-1.884$ & 0.000 \\
\hline \multicolumn{7}{|l|}{$E R$} \\
\hline Negative & Reference & & & Reference & & \\
\hline Positive & 0.244 & $0.141-0.423$ & 0.000 & 0.219 & $0.127-0.380$ & 0.000 \\
\hline \multicolumn{7}{|l|}{$P R$} \\
\hline Negative & Reference & & & Reference & & \\
\hline Positive & 0.551 & $0.473-0.641$ & 0.000 & 0.517 & $0.442-0.604$ & 0.000 \\
\hline \multicolumn{7}{|l|}{ Insurance } \\
\hline No & Reference & & & Reference & & \\
\hline Yes & 0.721 & $0.558-0.931$ & 0.012 & 0.681 & $0.524-0.886$ & 0.004 \\
\hline
\end{tabular}


TABLE 2: Continued.

\begin{tabular}{|c|c|c|c|c|c|c|}
\hline \multirow{2}{*}{ Variable } & \multicolumn{3}{|c|}{ OS } & \multicolumn{3}{|c|}{ CSS } \\
\hline & $\mathrm{HR}$ & $95 \%$ CI & $\mathrm{P}$ & HR & $95 \%$ CI & $\mathrm{P}$ \\
\hline \multicolumn{7}{|c|}{ Marital status } \\
\hline No & Reference & & & Reference & & \\
\hline Yes & 0.770 & $0.686-0.864$ & 0.000 & 0.807 & $0.715-0.911$ & 0.001 \\
\hline
\end{tabular}

method, 3,171 BC patients with bone metastasis were finally obtained. The $\mathrm{R}$ software was used to randomly divide all patients into training group $(N=2,223)$ and validation group $(N=948)$ at a ratio of $7: 3$. Mean age and follow time of all were 60 years old (range, 21-97) and 30.2 months. In terms of race, $78.4 \%(n=2,485), 13.7 \%$ $(n=435)$, and $7.9 \%(n=251)$ of patients were white, black, and other races, respectively. The most general histological type was infiltrating duct carcinoma (IDC) $(n=2,285$, $72.1 \%)$. Moderate differentiation (Grade II) $(n=1,710$, $53.9 \%)$ accounted for more than half proportion, with poor differentiation (Grade III-IV) $(n=1048,33.0 \%)$ and good differentiation (Grade I) $(n=413,13.0 \%)$ following. Regarding size, the majority of patients have a tumor size greater than $20 \mathrm{~mm}(n=2,772,71.6 \%)$. Among the socioeconomic factors, only a few patients have no insurance $(n=118,3.7 \%)$. In the training group, almost half of all patients received chemotherapy $(n=1,058,47.6 \%)$. Only 849 patients (38.2\%) received surgery, 962 patients $(43.3 \%)$ receiving radiotherapy. Detailed demographics and clinical information of the training and validation groups were summarized in Table 1.

3.2. Confirmation of Prognostic Factors and Development Nomograms. We first conducted a univariate analysis to screen for relevant significant variables. The results of the univariate analysis on the training group can be viewed in Table 2. We obtained the significant $P$ value, HR (hazards ratio), and $95 \%$ confidence intervals (CI) of the relative importance of each independent variable, including demographic, clinical, and socioeconomic factors. Subsequently, we conducted a multivariate Cox regression analysis of significant variables. Through univariate and multivariate Cox regression analyses, 12 independent variables, in significant association with OS and CSS, were identified including age, race, histology grade, tumor size, primary site, surgery, brain metastasis, liver metastasis, lung metastasis, ER status, PR status, and insurance. The results of the multivariate Cox regression analysis of OS and CSS on the training group are shown in Table 3. Ultimately, the significant variables mentioned above were included to build the nomogram. The nomograms of OS and CSS are shown in Figures 2 and 3. Nomogram is a quite user-friendly predictive tool which enables clinician or patient to determine the survival probability by calculating the scores of covariate and then draw a line vertically downward [16]. The scores assigned to each factor were listed in Table 4.
3.3. Nomogram Validation and Risk Stratification. The performance of the nomograms was validated with $\mathrm{C}$-index, calibration plots, and DCA for discriminative ability, accurate prediction, and clinical utility, respectively. The Cindex of this model in the training group was 0.701 (95\% CI: $0.688-0.720$ ) for the OS model and 0.704 (95\% CI, 0.688-0.720) for the CSS model. In the validation group, the C-index of OS was $0.665(95 \% \mathrm{CI}$ : $0.63-0.692)$, while that of CCS was 0.678 (95\% CI, 0.651-0.705), underlying the good discriminating ability of the nomograms in the training and verification group. The prediction curves of OS and CSS in the training and validation groups at 1,3 , and 5 years were close to the standard curve $(Y=X)$, indicating that the prediction results of nomograms have a significant correlation with the actual observation (Figure 4). DCA of 1-, 3-, and 5-year OS and CSS showed that the nomograms had a higher net benefit in the training cohort and validation cohort, respectively (Figures 5 and 6). According to our OS nomogram and CSS nomogram, risk scores were calculated for each luminal A patient with bone metastasis. In addition, it has been tested by the Kaplan-Meier survival curve that patients of the low-risk group present better prognosis than those in the high-risk group (Figures 7 and 8).

\section{Discussion}

For patients of BC with bone metastasis, the long-term survival and life quality in the later period are still not optimistic, and yet convenient and accurate prognostic predicting tool lacks. Recent studies point that the prediction ability of nomograms may be superior to that of traditional, categorical predictive models for various outcomes associated with cancer [17-19]. To take a step further, we performed the first large-cohort and comprehensive retrospective study based on wide multicenter, where the OS and the CSS of luminal A patients with bone metastasis $(n=3,171)$ selected from the SEER database were retrospectively analyzed. Through univariate and multivariate Cox regression analyses, 12 independent variables associated with the OS and CSS were finally identified. Two nomograms established based on these significant prognosis predicting indicators showed high levels of discrimination and calibration in clinical utility.

Although BC bone metastasis is still incurable, our survival curves showed that the survival probability for patients of the low-risk group is significantly higher than those of the high-risk group. Therefore, it appears to be 
TABLE 3: Multivariate Cox regression analysis of overall survival and cancer-specific survival in the training group.

\begin{tabular}{|c|c|c|c|c|c|c|}
\hline \multirow{2}{*}{ Variable } & \multicolumn{3}{|c|}{ OS } & \multicolumn{3}{|c|}{ CSS } \\
\hline & HR & $95 \% \mathrm{CI}$ & $\mathrm{P}$ & HR & $95 \% \mathrm{CI}$ & $\mathrm{P}$ \\
\hline \multicolumn{7}{|l|}{ Age $(y)$} \\
\hline$<55$ & 1 & & & 1 & & \\
\hline $55-78$ & 1.218 & $1.068-1.390$ & 0.003 & 1.204 & $1.031-1.405$ & 0.019 \\
\hline$>78$ & 2.476 & $2.039-3.006$ & 0.000 & 2.137 & $1.697-2.692$ & 0.000 \\
\hline \multicolumn{7}{|l|}{ Size $(\mathrm{mm})$} \\
\hline$<36$ & 1 & & & 1 & & \\
\hline $36-85$ & 1.131 & $0.998-1.282$ & 0.053 & 1.078 & $0.925-1.257$ & 0.337 \\
\hline$>85$ & 1.363 & $1.118-1.661$ & 0.002 & 1.292 & $1.014-1.645$ & 0.038 \\
\hline \multicolumn{7}{|l|}{ Race } \\
\hline Black & 1 & & & 1 & & \\
\hline Other & 0.650 & $0.503-0.839$ & 0.001 & 0.724 & $0.553-0.946$ & 0.018 \\
\hline White & 0.641 & $0.546-0.752$ & 0.000 & 0.686 & $0.578-0.815$ & 0.000 \\
\hline \multicolumn{7}{|l|}{ Primary site } \\
\hline Breast, NOS & 1 & & & 1 & & \\
\hline Central portion & 0.744 & $0.578-0.958$ & 0.022 & 0.767 & $0.589-0.998$ & 0.048 \\
\hline Lower-inner quadrant & 1.021 & $0.825-1.264$ & 0.846 & 1.044 & $0.834-1.308$ & 0.706 \\
\hline Lower-outer quadrant & 0.823 & $0.693-0.978$ & 0.027 & 0.811 & $0.676-0.974$ & 0.025 \\
\hline Other & 0.975 & $0.833-1.142$ & 0.752 & 0.980 & $0.829-1.158$ & 0.811 \\
\hline \multicolumn{7}{|l|}{ Grade } \\
\hline I & 1 & & & 1 & & \\
\hline II & 1.297 & $1.063-1.583$ & 0.010 & 1.293 & $1.048-1.597$ & 0.017 \\
\hline III & 1.755 & $1.425-2.160$ & 0.000 & 1.806 & $1.450-2.249$ & 0.000 \\
\hline IV & 1.817 & $0.789-4.182$ & 0.160 & 1.949 & $0.843-4.506$ & 0.119 \\
\hline \multicolumn{7}{|l|}{ T stage } \\
\hline $\mathrm{T} 1, \mathrm{~T} 2$ & & & & 1 & & \\
\hline $\mathrm{T} 3, \mathrm{~T} 4$ & & & & 1.061 & $0.906-1.241$ & 0.463 \\
\hline \multicolumn{7}{|l|}{ Surgery } \\
\hline No & 1 & & & 1 & & \\
\hline Yes & 0.601 & $0.528-0.683$ & 0.000 & 0.593 & $0.518-0.680$ & 0.000 \\
\hline \multicolumn{7}{|l|}{ Brain metastasis } \\
\hline No & 1 & & & 1 & & \\
\hline Yes & 1.977 & $1.560-2.506$ & 0.000 & 2.003 & $1.566-2.562$ & 0.000 \\
\hline \multicolumn{7}{|l|}{ Liver metastasis } \\
\hline No & 1 & & & 1 & & \\
\hline Yes & 1.910 & $1.643-2.221$ & 0.000 & 2.016 & $1.726-2.355$ & 0.000 \\
\hline \multicolumn{7}{|l|}{ Lung metastasis } \\
\hline No & 1 & & & 1 & & \\
\hline Yes & 1.219 & $1.063-1.398$ & 0.005 & 1.185 & $1.026-1.370$ & 0.021 \\
\hline \multicolumn{7}{|l|}{$E R$} \\
\hline Negative & 1 & & & 1 & & \\
\hline Positive & 0.272 & $0.156-0.477$ & 0.000 & 0.235 & $0.134-0.413$ & 0.000 \\
\hline \multicolumn{7}{|l|}{$P R$} \\
\hline Negative & 1 & & & 1 & & \\
\hline Positive & 0.634 & $0.543-0.740$ & 0.000 & 0.587 & $0.501-0.689$ & 0.000 \\
\hline Borderline & 2.336 & $0.739-7.388$ & 0.149 & 2.167 & $0.683-6.877$ & 0.189 \\
\hline \multicolumn{7}{|l|}{ Insurance } \\
\hline No & 1 & & & 1 & & \\
\hline Yes & 0.755 & $0.581-0.980$ & 0.035 & 0.727 & $0.556-0.950$ & 0.020 \\
\hline \multicolumn{7}{|l|}{ Marital } \\
\hline No & & & & 1 & & \\
\hline Yes & & & & 0.916 & $0.807-1.040$ & 0.176 \\
\hline
\end{tabular}


Coxph regression

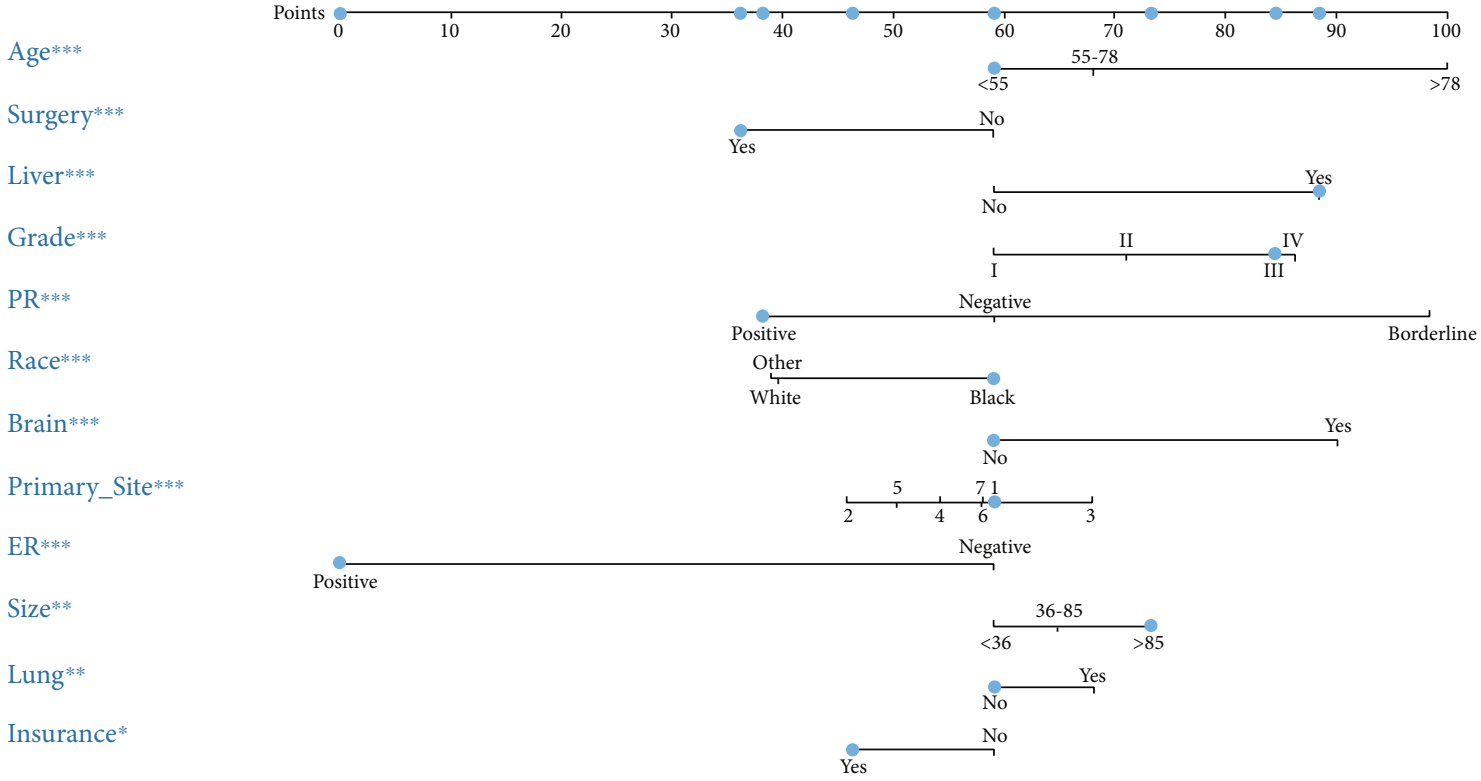

Total-points-to-outcome nomogram:

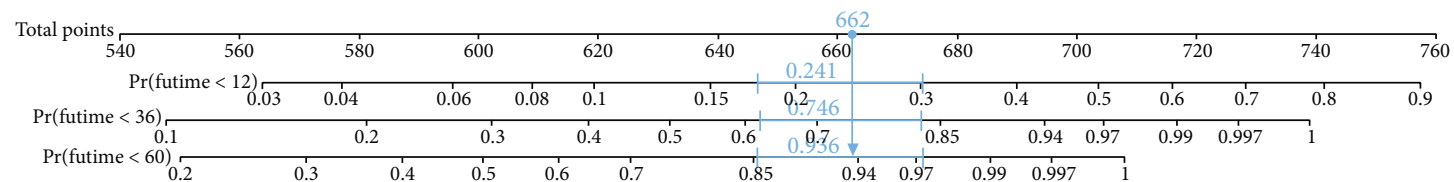

FIGURE 2: The novel nomogram to predict 1-, 3-, and 5-year overall survival of luminal A BC patients with bone metastasis.

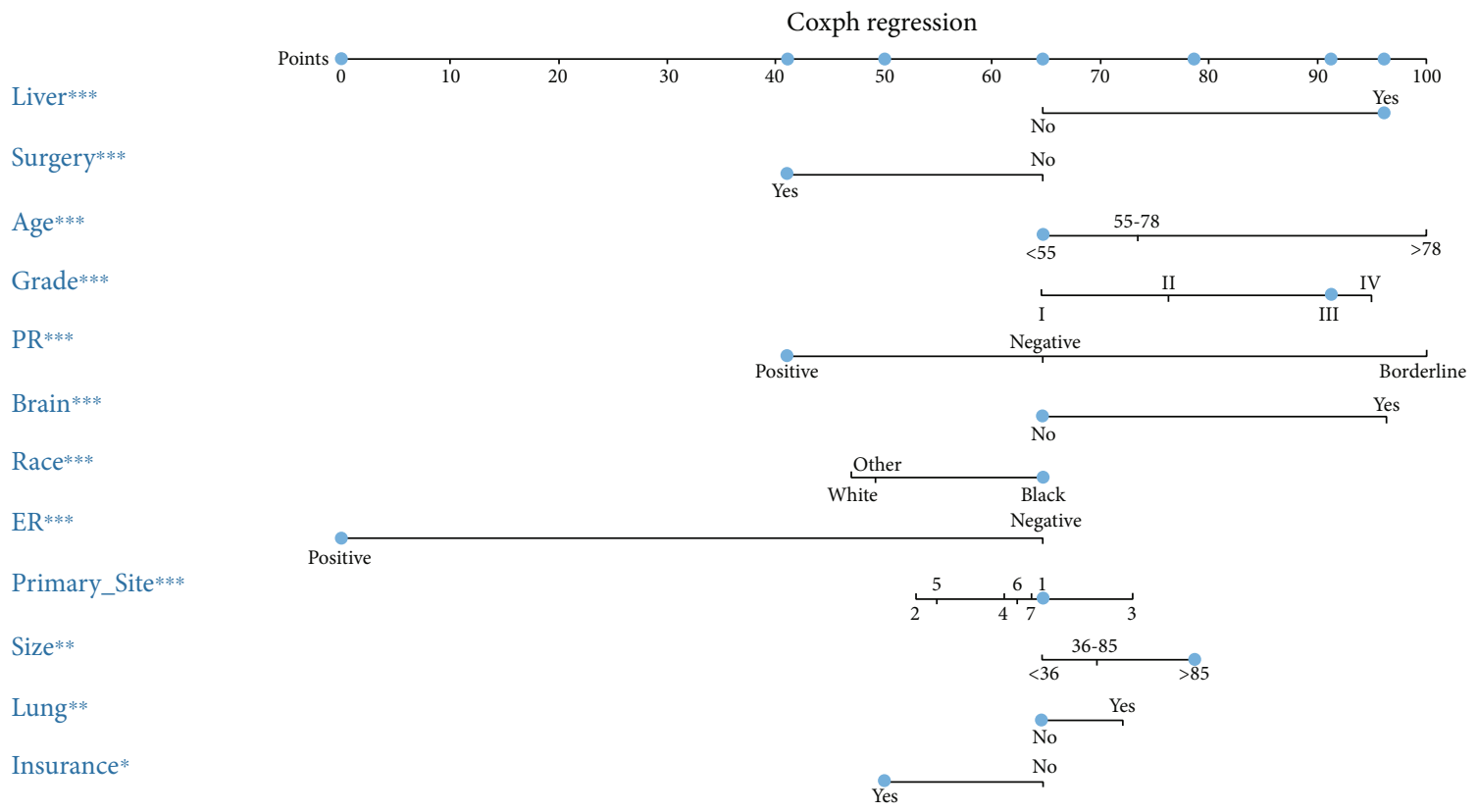

Total-points-to-outcome nomogram:

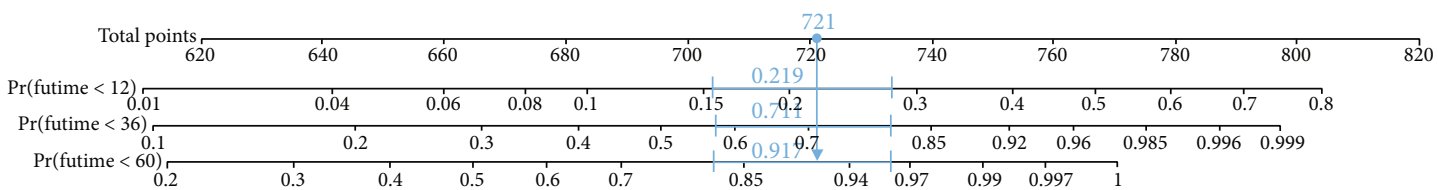

FIGURE 3: The novel nomogram to predict 1-, 3-, and 5-year cancer-specific survival of luminal A BC patients with bone metastasis. 
TABLE 4: Value assignment of the independent prognostic factors contained in the OS-and CSS-nomograms.

\begin{tabular}{|c|c|c|}
\hline Prognostic factors & OS & CSS \\
\hline \multicolumn{3}{|l|}{ Age $(y)$} \\
\hline$<55$ & 59 & 65 \\
\hline $55-78$ & 68 & 73 \\
\hline$>78$ & 100 & 100 \\
\hline \multicolumn{3}{|l|}{ Size $(m m)$} \\
\hline$<36$ & 59 & 65 \\
\hline $36-85$ & 65 & 70 \\
\hline$>85$ & 73 & 79 \\
\hline \multicolumn{3}{|l|}{ Race } \\
\hline Black & 59 & 65 \\
\hline Other & 40 & 49 \\
\hline White & 39 & 47 \\
\hline \multicolumn{3}{|l|}{ Primary site } \\
\hline Breast, NOS & 59 & 65 \\
\hline Central portion of breast & 46 & 53 \\
\hline Lower-inner quadrant of breast & 68 & 73 \\
\hline Lower-outer quadrant of breast & 54 & 61 \\
\hline Upper-inner quadrant of breast & 58 & 62 \\
\hline Upper-outer quadrant of breast & 58 & 64 \\
\hline Other & 50 & 55 \\
\hline \multicolumn{3}{|l|}{ Grade } \\
\hline I & 59 & 65 \\
\hline II & 71 & 76 \\
\hline III & 85 & 91 \\
\hline IV & 86 & 95 \\
\hline \multicolumn{3}{|l|}{ Surgery } \\
\hline No & 59 & 65 \\
\hline Yes & 36 & 41 \\
\hline \multicolumn{3}{|l|}{ Brain metastasis } \\
\hline No & 59 & 65 \\
\hline Yes & 90 & 96 \\
\hline \multicolumn{3}{|l|}{ Liver metastasis } \\
\hline No & 59 & 65 \\
\hline Yes & 88 & 96 \\
\hline \multicolumn{3}{|l|}{ Lung metastasis } \\
\hline No & 59 & 65 \\
\hline Yes & 68 & 72 \\
\hline \multicolumn{3}{|l|}{$E R$} \\
\hline Negative & 59 & 65 \\
\hline Positive & 0 & 0 \\
\hline \multicolumn{3}{|l|}{$P R$} \\
\hline Negative & 59 & 65 \\
\hline Positive & 38 & 41 \\
\hline Borderline & 98 & 100 \\
\hline \multicolumn{3}{|l|}{ Insurance } \\
\hline No & 59 & 65 \\
\hline Yes & 46 & 50 \\
\hline
\end{tabular}

crucial to identify the risk factors for facilitating the prognosis prediction. Consistent with previous studies, our study suggests that age is a strong independent prognostic factor and young age is an advantageous factor for good prognosis [20, 21]. Besides, a report focusing on the OS time trends indicates that every incremental year of age is in independent and significant association with a higher risk of death [22]. On the contrary, old age may be a disadvantageous factor with poor status and age-related comorbidities. In addition, some targeted therapy or other intensive systemic treatment may be contraindicated to the old patients who are vulnerable to more frequent causes of death. In line with our conclusion, it has been previously reported that race is a significant survival predictor [23]. Parada et al. [24] pointed out that racial differences in gene expression might lead to the survival disparity of BC patients. Our study shows that insurance status is also a significant variable. In many states of the USA, health insurance not only compensated patients for surgery but also reduced the cost of systemic adjuvant treatments. And insurance status has shown its impact on stages of diagnosis in a previous study [25]. Moreover, Pan et al. [23] developed that in addition to the impact on diagnosis, uninsured status was also demonstrated to be an unfavorable factor of poor OS and CSS.

In our conclusion, tumor size, tumor primary site, and histology grade were recognized as risk factors of great importance in affecting the prognosis of BC patients, which were in accordance with previous studies [26-29]. With our regression analyses, brain, liver, and lung metastasis were also independent predictors of prognosis, among which brain metastasis was most likely to result in poor prognosis, followed by liver and lung metastasis. When considering all BC patients as an entire population, a cohort study has found that different distant metastatic sites presented similar trends in affecting survival [30]. Moreover, the effective implications of ER and PR status have been demonstrated by some largescale studies in predicting patients' prognosis and responding to BC endocrine therapy $[31,32]$. Seho et al. [33] also concluded that lack of expression of either ER or PR was in association with worse prognosis, especially among patients with node-positive luminal A subtype.

For cancer patients who have been metastasized, to perform surgery is still controversial. Similar to previous reports, our research showed that nonsurgical luminal A patients with bone metastasis had an unfavorable prognosis. Generally, surgical treatment for primary lesion is recognized as a palliative therapy for BC patients with metastasis. Gnerlich et al. [34] showed an association between receiving surgery and improved survival for $\mathrm{BC}$ patients with metastasis. Xiong et al. [35] pointed that the prognosis of certain stage IV BC patients, especially those with bone- or soft tissue-only metastasis, could be improved by surgical removal of primary lesions. Moreover, for BC patients with bone metastasis, surgery can not only prolong the survival time but also improve life quality to some extent. And it is generally believed that chemotherapy can exert a similar effect by reducing cancer-related complications through killing or inhibiting 

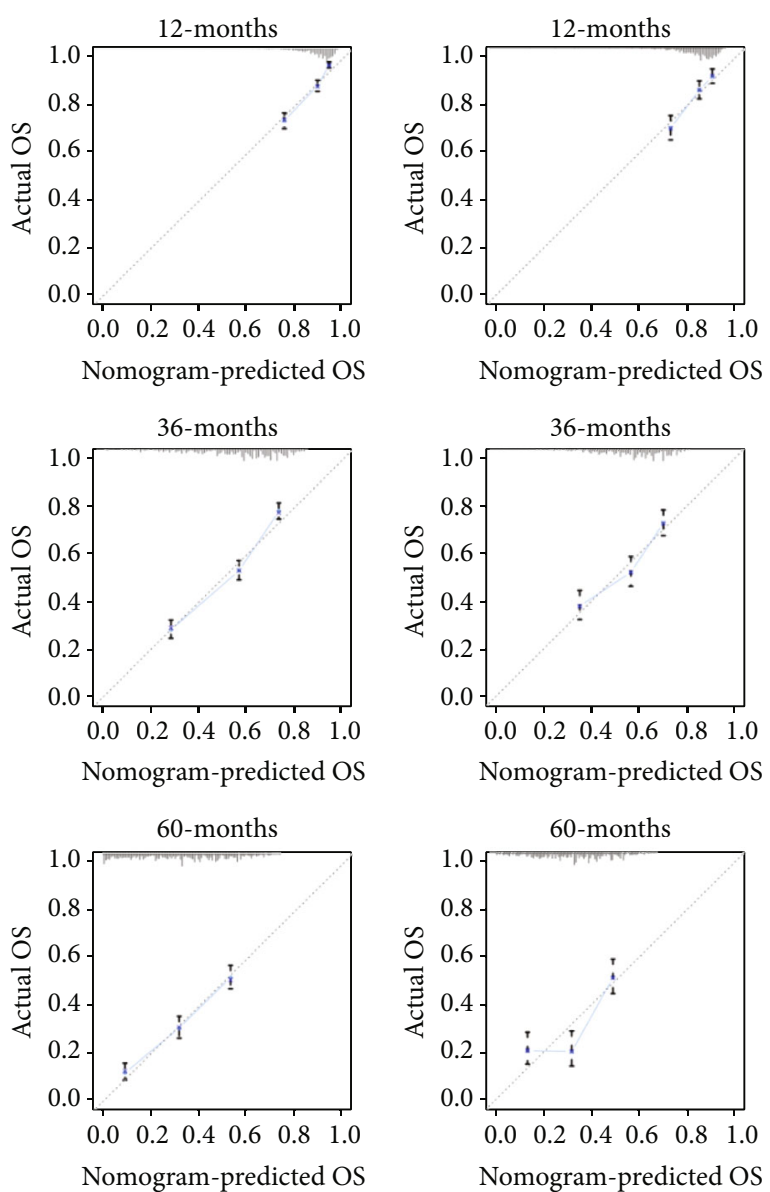

(a)

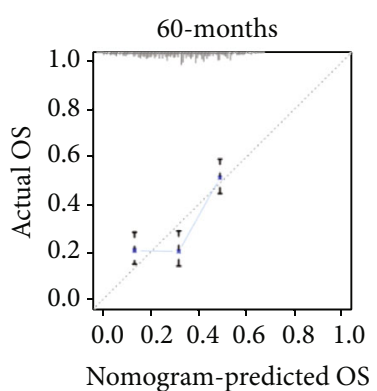

(b)
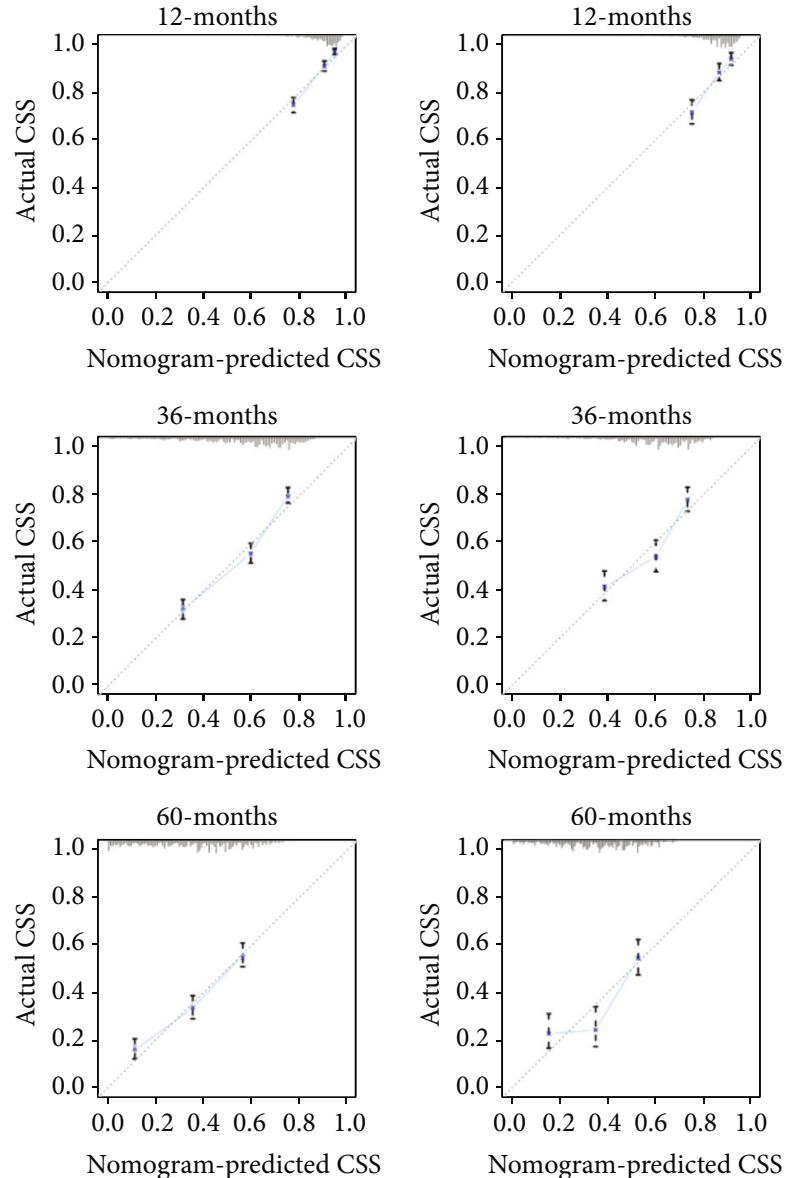

(c)

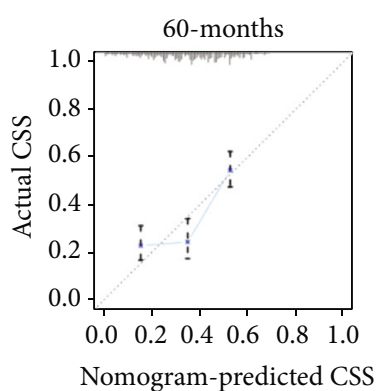

(d)

FIGURE 4: Calibration curves for predicting patients overall survival at 1-, 3-, and 5- years in the training cohort (a) and validation cohort (b). Calibration curves for predicting patient cancer-specific survival at 1-, 3-, and 5- years in the training cohort (c) and validation cohort (d).

cancer cells, thereby relapse delayed and survival time prolonged. However, chemotherapy failed to be identified as a significant predictor for either OS or CSS in our multivariate analysis. In fact, our conclusion is not an exception with support of other studies, where no benefit of adjuvant chemotherapy was detected in luminal A BC patients [36, 37]. The Panel of the St. Gallen International Expert Consensus insisted that was less useful in Luminal A subtype patients for their less responsiveness to chemotherapy [38]. In addition, consistent with our results, a retrospective cohort study suggested that there was no significant effect of radiotherapy in improving survival of BC with metastasis [39].

To our knowledge, this study is the first to construct comprehensive nomograms to predict the prognosis of Luminal A BC patients with bone metastasis. Our nomograms were based on twelve independent and significant prognosis factors selected from univariate and multivariate Cox regression analyses with satisfied level of discrimination, calibration, and clinical utility, which can help predict the survival probability and expected benefits of different treatments, so that the most suitable one can be selected and the prognosis can get improved. In addition, there are many kinds of predictors included in our nomograms, implying that the luminal A with bone metastasis is a complex disease with considerable individual differences. In recent years, against the increasing emphasis on personalization of cancer treatment strategies, our nomograms can make accurate individualized predictions for each luminal A subtype patient with bone metastasis. By adding the scores of each variable, the physician can clearly assess the prognosis of the patient. Combined with the evaluation results, for high-risk patients, more appropriate treatments and more optimized care can be provided. In contrast, for low-risk patients, some treatment and examinations can be appropriately adjusted or reduced, thereby lessening the patient's physical and economic burden.

However, there are several limitations in the present research. First, our nomograms were based on a retrospective cohort obtained from SEER-base, which inevitably creates bias. Second, the data may lack some potentially important variables and key indicators, such as related biomarkers, hormone therapy, targeted therapy, recurrence, and other advanced technologies. Third, some data are missing or not in detail, especially specific locations of bone metastasis and types of surgery. These deficiencies remain to be further improved in future studies. 

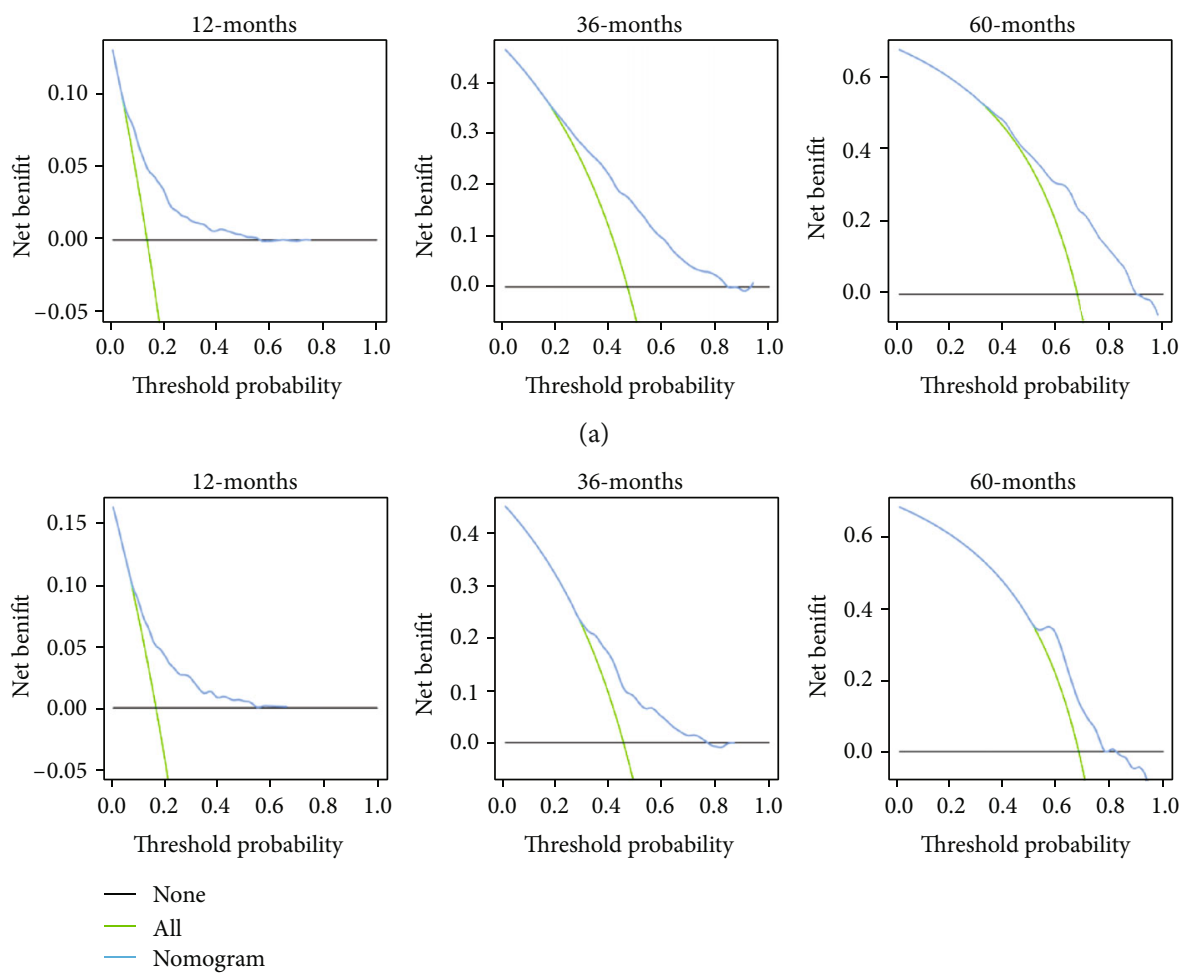

(b)

FIGURE 5: The decision curve analysis of the nomogram for predicting 1-, 3-, and 5-year overall survival in the training cohort (a) and in the validation cohort (b).
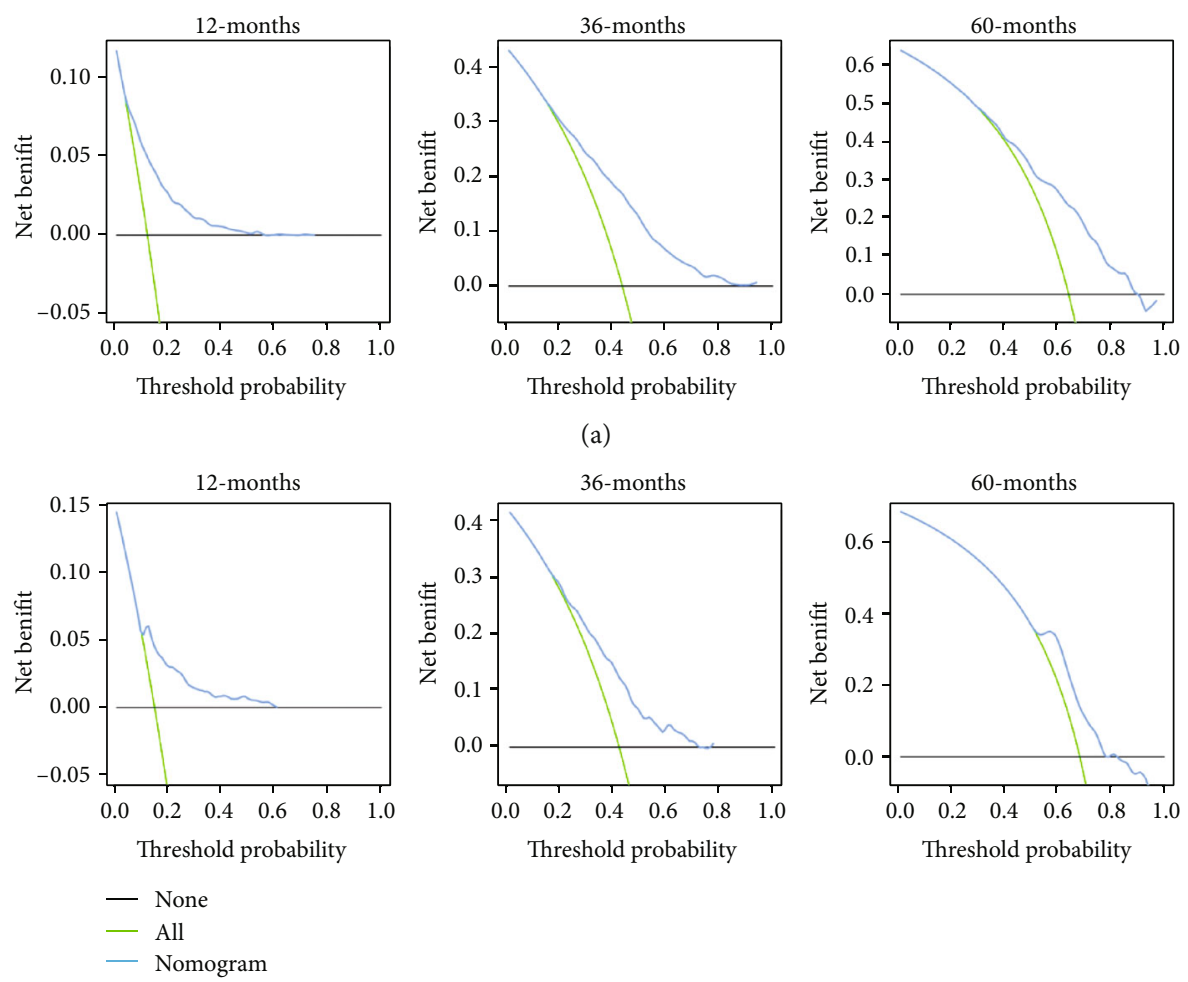

(b)

FIgURE 6: The decision curve analysis of the nomogram for predicting 1-, 3-, and 5-year cancer-specific survival in the training cohort (a) and in the validation cohort (b). 

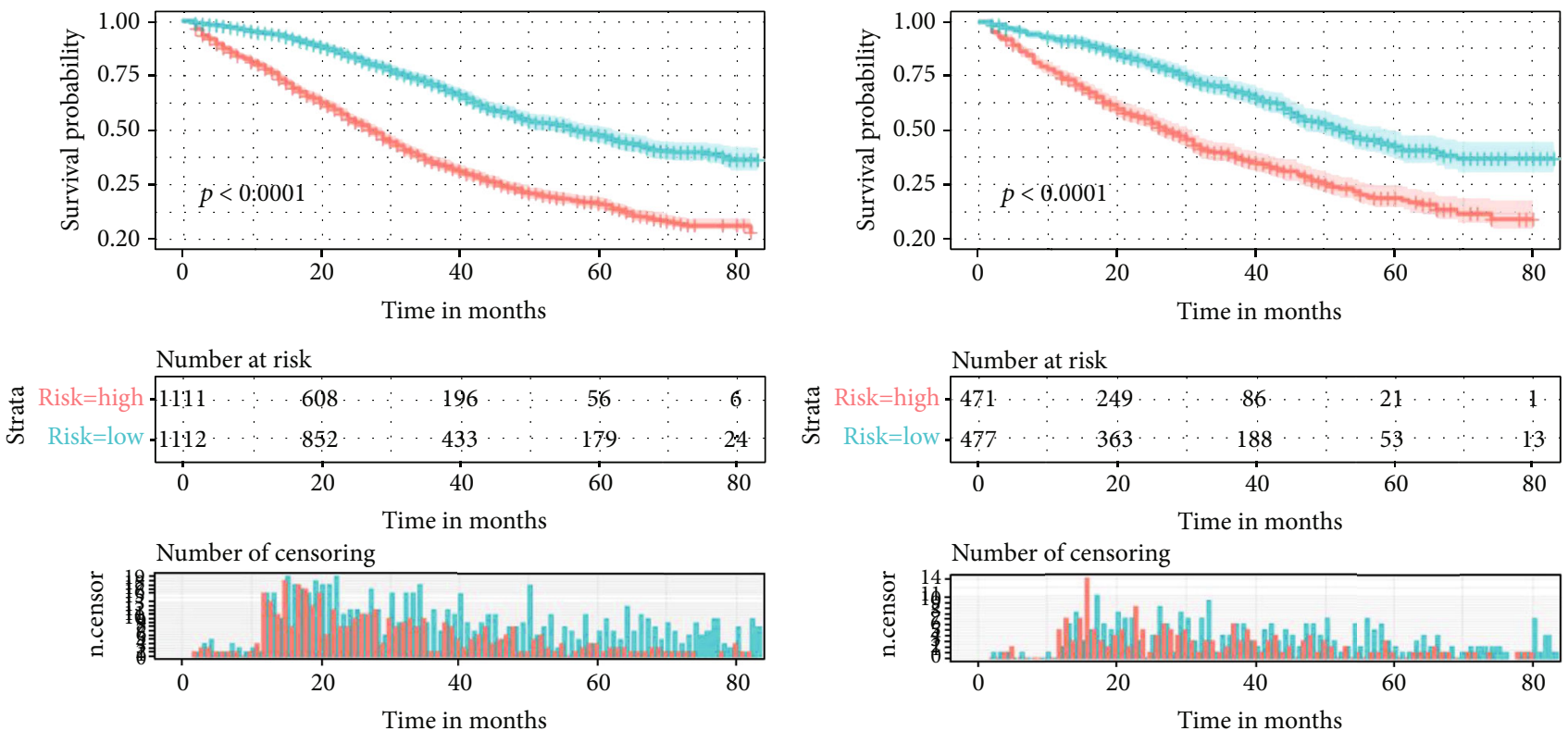

Number of censoring

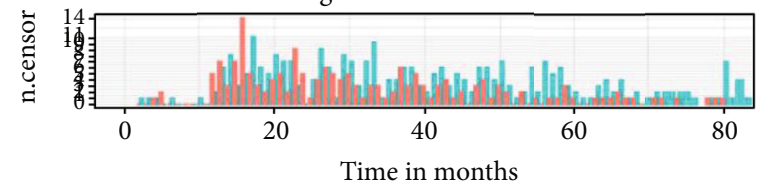

Strata
+ Risk=high
+ Risk=low

(a)

(b)

Figure 7: The Kaplan-Meier survival curve of risk group stratification for overall survival in the training cohort (a) and in the validation cohort (b).
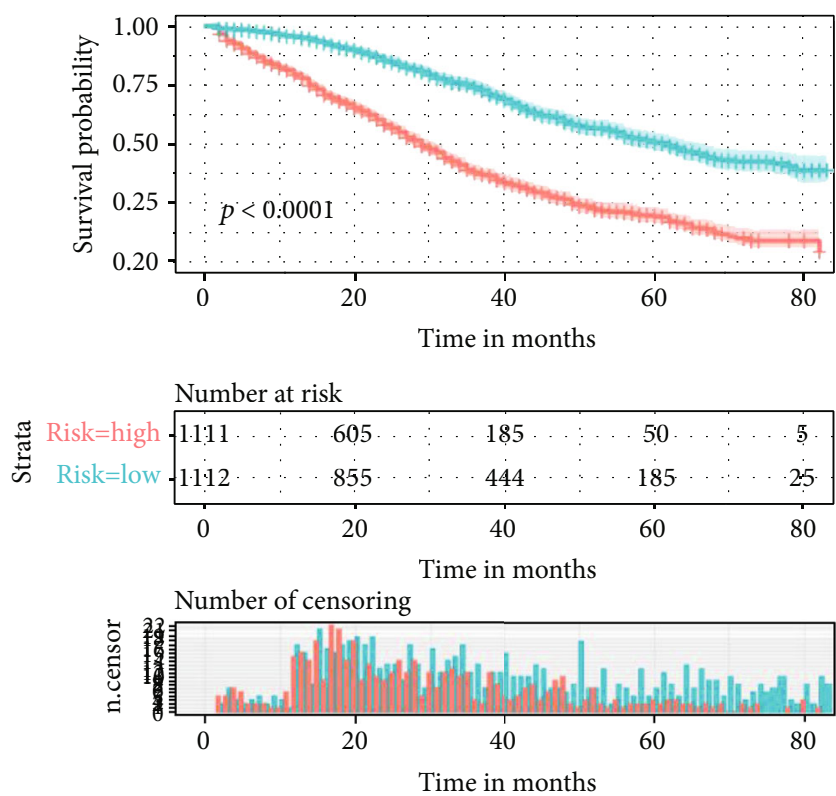

Strata

+ Risk=high

+ Risk=low

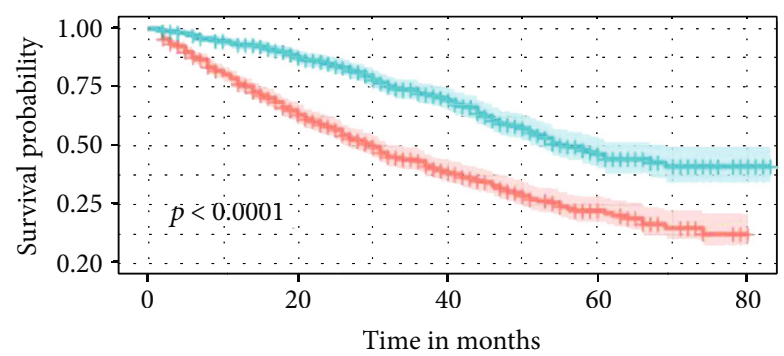

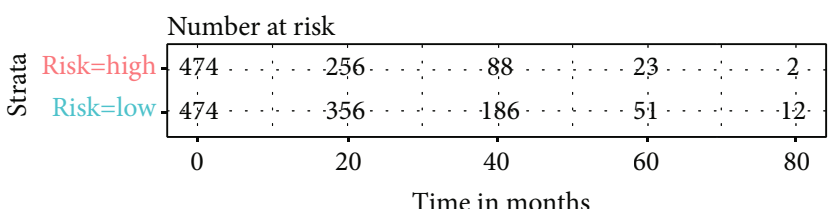

Number of censoring

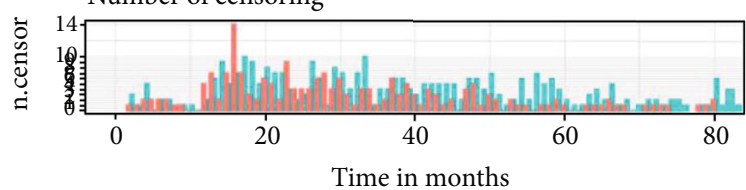

(b)

Figure 8: The Kaplan-Meier survival curve of risk group stratification for cancer-specific survival in training cohort (a) and in the validation cohort (b). 


\section{Conclusions}

Our study identified twelve independent prognostic factors for OS and CSS of luminal A BC patients with bone metastasis. The nomograms we developed can accurately and effectively predict the survival information of patients and may facilitate clinical decision-making.

\section{Abbreviations}

$\begin{array}{ll}\text { BC: } & \text { Breast cancer } \\ \text { OS: } & \text { Overall survival } \\ \text { CSS: } & \text { Cancer-specific survival } \\ \text { SEER: } & \text { Surveillance, epidemiology, and end results } \\ \text { ER: } & \text { Estrogen receptor } \\ \text { PR: } & \text { Progesterone receptor } \\ \text { Her2: } & \text { Human epidermal growth factor receptor } 2 \\ \text { C-index: } & \text { Concordance index } \\ \text { DCA: } & \text { Decision curve analysis. }\end{array}$

\section{Data Availability}

The data analyzed during the study are available from the SEER data set repository and/or authors.

\section{Ethical Approval}

The study protocol was approved by the SEER program from the National Cancer Institute, US (reference number 15260Nov2018).

\section{Consent}

There is no need for informed consent in our study since the unidentified data was free from medical ethics review.

\section{Conflicts of Interest}

All authors declare that they have no potential conflict of interest.

\section{Authors' Contributions}

QH T and C H had the idea of and designed this study. QH T, $\mathrm{C} \mathrm{H}$, and $\mathrm{H} \mathrm{Z}$ collected the data. QH T, C P, and M K analyzed the data. QH T, C H, and YJ W generated the figures and tables. QH T wrote the manuscript. C H, YJ W, MX S, JY L, CL Z, C W, and C Z helped to review and revision of the manuscript. XX M supervised the research. All authors reviewed the results and approved the final version of the article.

\section{Acknowledgments}

This study was funded by the National Natural Science Foundation of China, grant numbers 81871804 and 81672200; the National Key Research and Development Program of China, grant number 2019YFC0121400.

\section{References}

[1] F. Bray, J. Ferlay, I. Soerjomataram, R. L. Siegel, L. A. Torre, and A. Jemal, "Global cancer statistics 2018: GLOBOCAN estimates of incidence and mortality worldwide for 36 cancers in 185 countries," CA: A Cancer Journal for Clinicians, vol. 68, no. 6, pp. 394-424, 2018.

[2] A. Goldhirsch, E. P. Winer, A. S. Coates et al., "Personalizing the treatment of women with early breast cancer: highlights of the St Gallen International Expert Consensus on the primary therapy of early breast cancer 2013," Annals of oncology : official journal of the European Society for Medical Oncology, vol. 24, no. 9, pp. 2206-2223, 2013.

[3] T. Sørlie, R. Tibshirani, J. Parker et al., "Repeated observation of breast tumor subtypes in independent gene expression data sets," Proceedings of the National Academy of Sciences of the United States of America, vol. 100, no. 14, pp. 8418-8423, 2003.

[4] L. Genre, H. Roché, L. Varela et al., "External validation of a published nomogram for prediction of brain metastasis in patients with extra-cerebral metastatic breast cancer and risk regression analysis," European Journal of Cancer, vol. 72, pp. 200-209, 2017.

[5] R. Siegel, D. Naishadham, and A. Jemal, "Cancer statistics for Hispanics/Latinos, 2012," CA: A Cancer Journal for Clinicians, vol. 62, no. 5, pp. 283-298, 2012.

[6] W. Xiao, S. Zheng, A. Yang et al., "Breast cancer subtypes and the risk of distant metastasis at initial diagnosis: a populationbased study," Cancer Management and Research, vol. 10, pp. 5329-5338, 2018.

[7] R. E. Coleman, "Bisphosphonates: clinical experience," The Oncologist, vol. 9, no. S4, pp. 14-27, 2004.

[8] H. Miyashita, C. Cruz, and S. Malamud, "Risk factors for skeletal-related events in patients with bone metastasis from breast cancer undergoing treatment with zoledronate," Breast cancer research and treatment, vol. 182, no. 2, pp. 381-388, 2020.

[9] A. Iasonos, D. Schrag, G. V. Raj, and K. S. Panageas, "How to build and interpret a nomogram for cancer prognosis," Journal of Clinical Oncology, vol. 26, no. 8, pp. 1364-1370, 2008.

[10] M. W. Kattan, J. A. Eastham, A. M. F. Stapleton, T. M. Wheeler, and P. T. Scardino, "A preoperative nomogram for disease recurrence following radical prostatectomy for prostate cancer," Journal of Urology, vol. 161, no. 1, pp. 354-355, 1999.

[11] S. F. Shariat, U. Capitanio, C. Jeldres, and P. I. Karakiewicz, "Can nomograms be superior to other prediction tools?," BJU International, vol. 103, no. 4, pp. 492-497, 2009.

[12] Z. Wang, S. Li, Y. Li et al., "Prognostic factors for survival among patients with primary bone sarcomas of small bones," Cancer Management and Research, vol. Volume 10, pp. 1191-1199, 2018.

[13] S. Baker, K. Bakunina, M. Duijm et al., "Development and external validation of a nomogram to predict overall survival following stereotactic body radiotherapy for early-stage lung cancer," Radiation oncology (London, England), vol. 15, no. 1, p. $89,2020$.

[14] P. Capogrosso and A. J. Vickers, "A Systematic Review of the Literature Demonstrates Some Errors in the Use of Decision Curve Analysis but Generally Correct Interpretation of Findings," Medical Decision Making, vol. 39, no. 5, pp. 493-498, 2019.

[15] M. Fitzgerald, B. R. Saville, and R. J. Lewis, "Decision curve analysis," JAMA, vol. 313, no. 4, pp. 409-410, 2015. 
[16] Z. Wang, Y. Cheng, S. Chen et al., "Novel prognostic nomograms for female patients with breast cancer and bone metastasis at presentation," Annals of Translational Medicine, vol. 8, no. 5, p. 197, 2020.

[17] N. F. Marko, Z. Xu, T. Gao, M. W. Kattan, and R. J. Weil, "Predicting survival in women with breast cancer and brain metastasis: a nomogram outperforms current survival prediction models," Cancer, vol. 118, no. 15, pp. 3749-3757, 2012.

[18] T. Hong, D. Cai, L. Jin et al., "Development and validation of a nomogram to predict survival after curative resection of nonmetastatic colorectal cancer," Cancer medicine, vol. 9, no. 12, pp. 4126-4136, 2020.

[19] C. N. Sternberg, "Are nomograms better than currently available stage groupings for bladder cancer?," Journal of Clinical Oncology, vol. 24, no. 24, pp. 3819-3820, 2006.

[20] S. Frank, M. Carton, C. Dubot et al., "Impact of age at diagnosis of metastatic breast cancer on overall survival in the real-life ESME metastatic breast cancer cohort," Breast, vol. 52, pp. 50$57,2020$.

[21] R. Largillier, J.-M. Ferrero, J. Doyen et al., "Prognostic factors in 1,038 women with metastatic breast cancer," Annals of oncology : official journal of the European Society for Medical OncologyAnnals of oncology : official journal of the European Society for Medical Oncology, vol. 19, no. 12, pp. 2012-2019, 2008.

[22] E. Gobbini, M. Ezzalfani, V. Dieras et al., “Time trends of overall survival among metastatic breast cancer patients in the reallife ESME cohort," European journal of cancer, vol. 96, pp. 1724, 2018

[23] H. Y. Pan, G. V. Walker, S. R. Grant et al., "Insurance status and racial disparities in cancer-specific mortality in the United States: a population-based analysis," Cancer Epidemiology Biomarkers \& Prevention, vol. 26, no. 6, pp. 869-875, 2017.

[24] H. Parada Jr., X. Sun, J. M. Fleming et al., "Race-associated biological differences among luminal A and basal-like breast cancers in the Carolina Breast Cancer Study," Breast Cancer Research, vol. 19, no. 1, p. 131, 2017.

[25] P. Ji, Y. Gong, C. C. Jiang, X. Hu, G. H. Di, and Z. M. Shao, "Association between socioeconomic factors at diagnosis and survival in breast cancer: A population-based study," Cancer medicine, vol. 9, no. 5, pp. 1922-1936, 2020.

[26] C. Siotos, M. McColl, K. Psoter et al., "Tumor Site and Breast Cancer Prognosis," Clinical breast cancer, vol. 18, no. 5, pp. e1045-e1052, 2018.

[27] J. S. Michaelson, M. Silverstein, J. Wyatt et al., "Predicting the survival of patients with breast carcinoma using tumor size," Cancer, vol. 95, no. 4, pp. 713-723, 2002.

[28] J. Diessner, M. Wischnewsky, T. Stüber et al., "Evaluation of clinical parameters influencing the development of bone metastasis in breast cancer," BMC Cancer, vol. 16, no. 1, 2016.

[29] G. Contesso, H. Mouriesse, S. Friedman, J. Genin, D. Sarrazin, and J. Rouesse, "The importance of histologic grade in longterm prognosis of breast cancer: a study of 1,010 patients, uniformly treated at the Institut Gustave-Roussy," Journal of Clinical Oncology, vol. 5, no. 9, pp. 1378-1386, 1987.

[30] K. M. Sjoquist, L. A. Renfro, R. J. Simes et al., "Personalizing Survival Predictions in Advanced Colorectal Cancer: The ARCAD Nomogram Project," JNCI: Journal of the National Cancer Institute, vol. 110, no. 6, pp. 638-648, 2018.

[31] S. Liu, S. K. Chia, E. Mehl et al., "Progesterone receptor is a significant factor associated with clinical outcomes and effect of adjuvant tamoxifen therapy in breast cancer patients," Breast Cancer Research and Treatment, vol. 119, no. 1, pp. 53-61, 2010.

[32] E. A. Rakha, M. E. El-Sayed, A. R. Green et al., "Biologic and Clinical Characteristics of Breast Cancer With Single Hormone Receptor-Positive Phenotype," Journal of Clinical Oncology, vol. 25, no. 30, pp. 4772-4778, 2007.

[33] S. Park, B.-W. Park, T. H. Kim et al., "Lack of either estrogen or progesterone receptor expression is associated with poor survival outcome among luminal A breast cancer subtype," Annals of surgical oncology, vol. 20, no. 5, pp. 1505-1513, 2013.

[34] Z. M. Rashaan, E. Bastiaannet, J. E. A. Portielje et al., "Surgery in metastatic breast cancer: patients with a favorable profile seem to have the most benefit from surgery," European Journal of Surgical Oncology (EJSO), vol. 38, no. 1, pp. 52-56, 2012.

[35] Z. Xiong, G. Deng, J. Wang et al., "Could local surgery improve survival in de novo stage IV breast cancer?," BMC cancer, vol. 18 , no. 1, p. 885, 2018.

[36] D. Herr, M. Wischnewsky, R. Joukhadar et al., "Does chemotherapy improve survival in patients with nodal positive luminal A breast cancer? A retrospective Multicenter Study," PloS one, vol. 14, no. 7, article e0218434, 2019.

[37] J. Diessner, M. Wischnewsky, M. Blettner et al., "Do Patients with Luminal A Breast Cancer Profit from Adjuvant Systemic Therapy? A Retrospective Multicenter Study," PloS one, vol. 11, no. 12, article e0168730, 2016.

[38] A. Goldhirsch, W. C. Wood, A. S. Coates et al., "Strategies for subtypes-dealing with the diversity of breast cancer: highlights of the St Gallen International Expert Consensus on the Primary Therapy of Early Breast Cancer 2011," Annals of Oncology, vol. 22, no. 8, pp. 1736-1747, 2011.

[39] M. Roayaei, Y. Nikanpour, and H. Mahdavi, "Effect of Surgery or Radiotherapy of the Breast on Survival in Metastatic Disease: a Retrospective Cohort Study," Indian journal of surgical oncology, vol. 10, no. 1, pp. 213-218, 2019. 